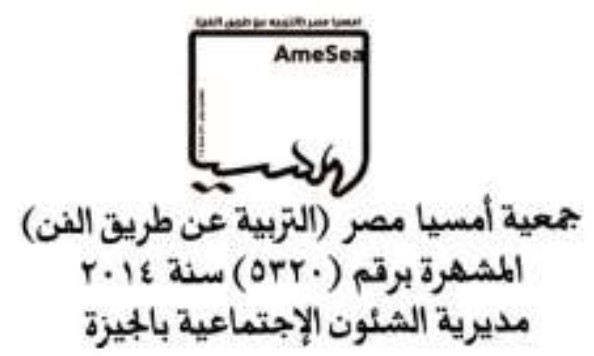

الامكانات التشكيلية لزهزة الحياة والاستفادة منها فى اتثراء التصميمات الزخرفية

Plastic potentials for the flower of life and benefit from it to enrich the decorative designs

إعداد/ أ.م.د إسلام كحم السيد هيبة

أستاذ التصميم المساعد كلية التربية النوعية جامعة المنوفية إنمية 


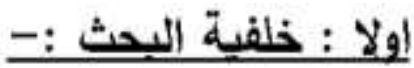

ان المنهج التقلى والثرجعية المنطقية التىى تبنى على اسس وقواعد وقوانين ونظم انشائية ذات اصول رياضية وعقلية من اهم مأيميز هذا الكون المنظم بجميع ظواهزه وبواطنه ، والذّى يخضع لضبط نظامي وفق مقاييس وقوانين أنشائية تتكرر في النماذج الطبيعية المختلفة سعيا التى الاتزان والتكيف البيئى، "تتمثل هذه المقاييس والقوانين في مجأميع من المنظومات الرقمية ، والتي تحقق التكافؤية الكونية و الاعثدائية بين جميع عناصر الكون (1). تلك النظم التي تتحكم في العناصر الكونية وتكوينات الطبيعة والتتى بلى بلى تعتبر المصدر الأساسي للفنان والمصدم ، " حيث تكمن القوانين و النظم الرياضية ، التي تفسر العلاقات المتوافقة ، التتي تحكم النظام الكوني بكافة

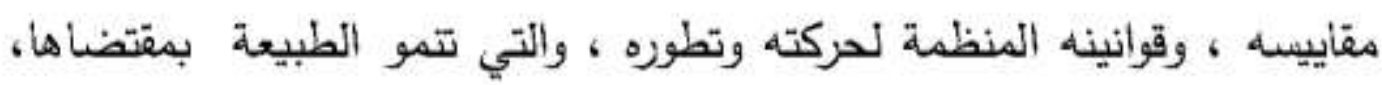

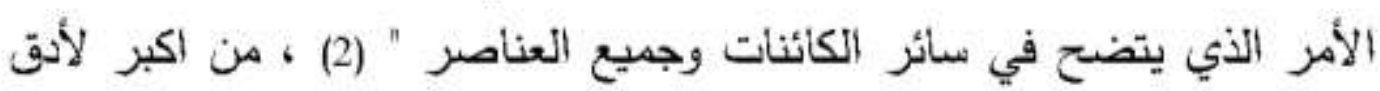
الخلايا وجزئيات المأدة . الكزي

كذلك الأمر ، فالفنون تتراوح مظهريا بين ما قد يبدو تثقائي غير منظم كتعيير مرئي يتبع الأحاسيس والانفعالات الداخلية لمبدعه ، وما ينتج عنها من من لرن

(1) -John A. Adam :" Mathematics in Nature : Modeling Patterns in the Natural World " Published by Princeton University Press. New York, 2003, P4

(2) - Gilbert A.:" The Mathematical Nature of Living World: The Power of Integration "World Scientific Publishing Co .PTE .LTD, USA, 2004, P 21. 


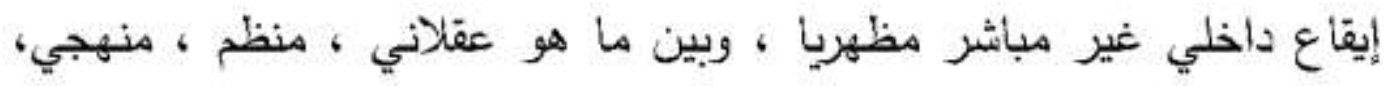

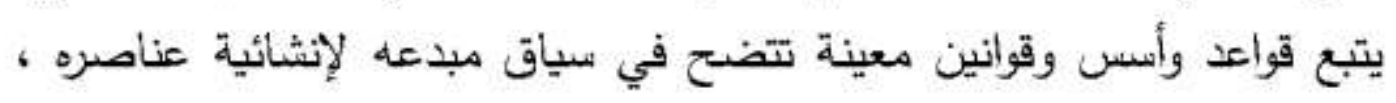

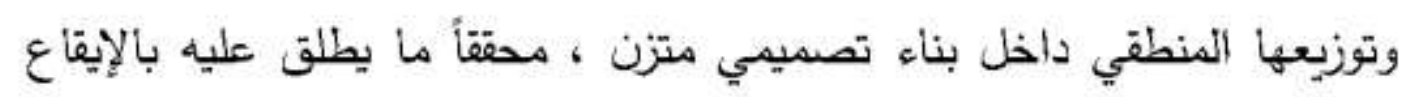

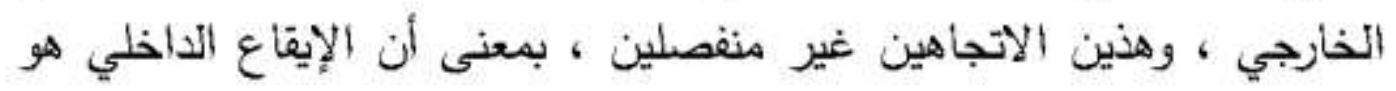

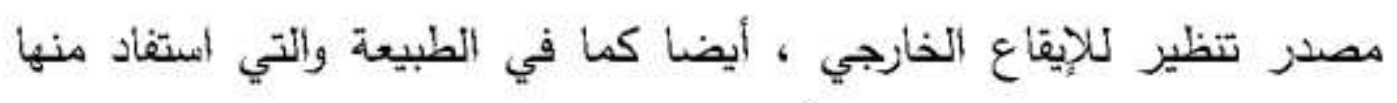

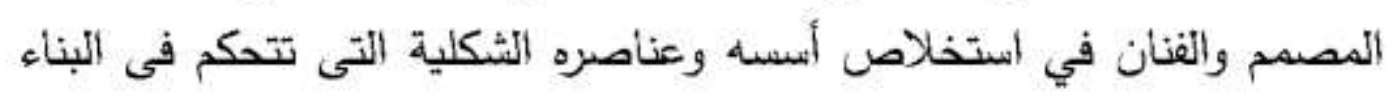

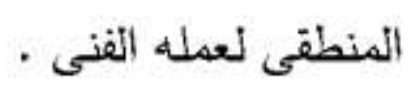
فا المنهج العقلي، والتتظيم المنطقي، ذو الأصول الرياضية، من أهم الهم

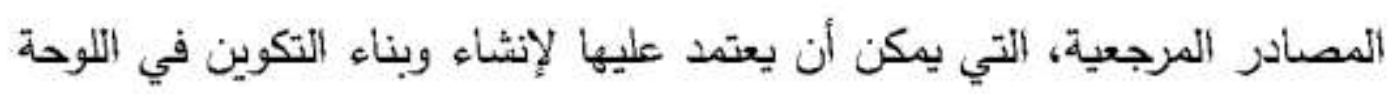

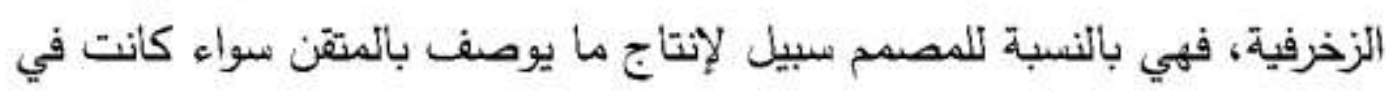

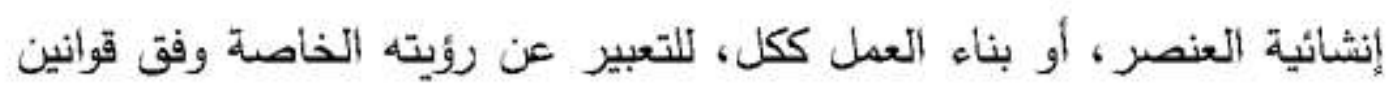

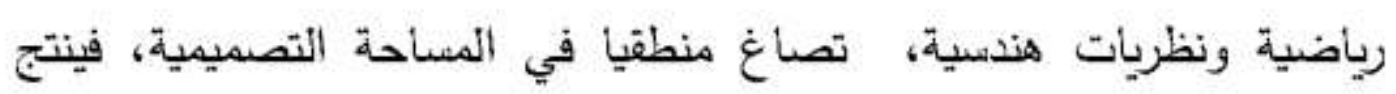

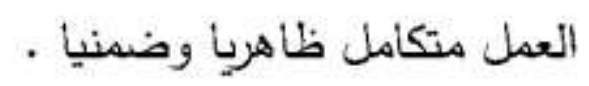

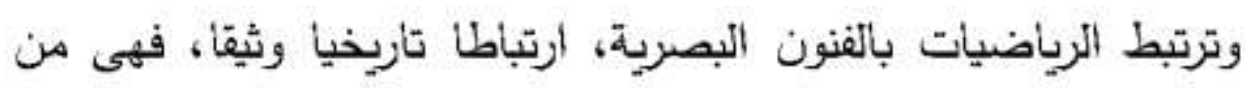

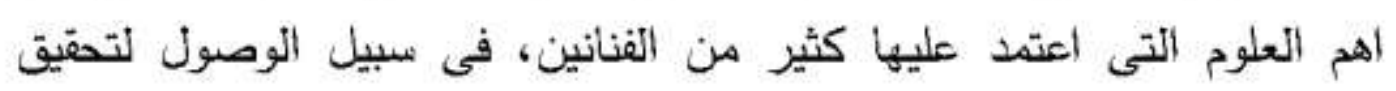

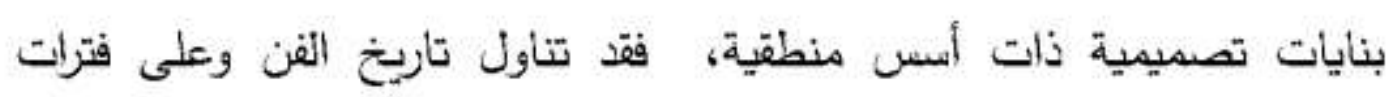
متلاحقة في عصور مختلفة، نظم أساسية تعتمد على منهج منطقي في التتاول

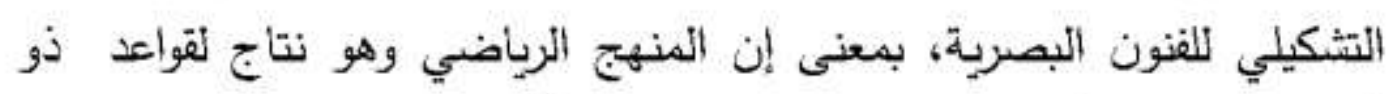
أصول عقلية هو أساس ثابت وان اختلفت اللغة أو الززمان.

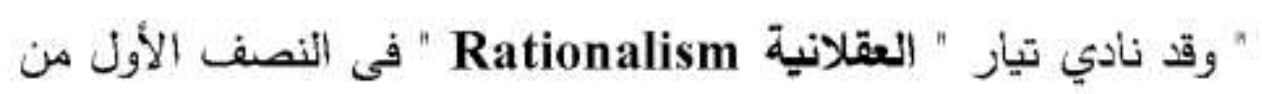

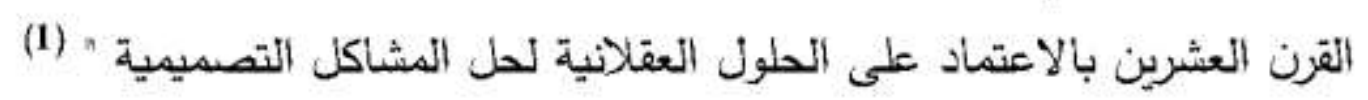

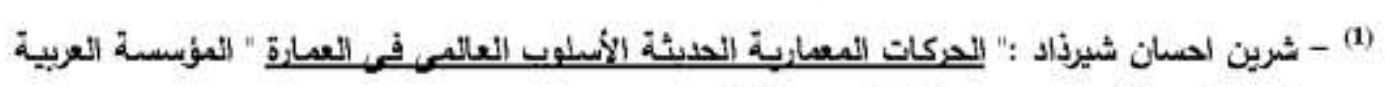

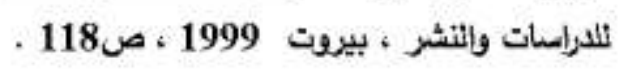


كما اجتمع على ذلك العديد من المدارس التفنية والاتجاهات الحديثة فى التصميم، حيث الاهتمام بذلك الجانب الادراكى والمبدأ النظامي في انثائيه وبناء الكيان التصميمي وتكوين المساحات التصميمية وصياغة العناصر التشكيلية وانخرط من تحتها العديد والعديد من الفنانين الذين تميزت أعمالهم الكان بذلك الطابع البنائي المتزن، كفلسفة تشكيليه، وكانوا بمثابة رموز وعلامات تدل

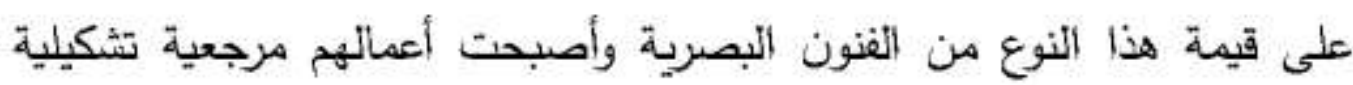
يبتقاد منها في بناء انشائيات تصميمية جديدة مستحثئة . ومن أهم المرجعيات الترياضية التي كانت مصدرا هأما للعديد من الثنات التطبيقات الفنية متتالية فيبوناتشي Fibonacci Sequence والنسبة الذهبية The Golden Ratio

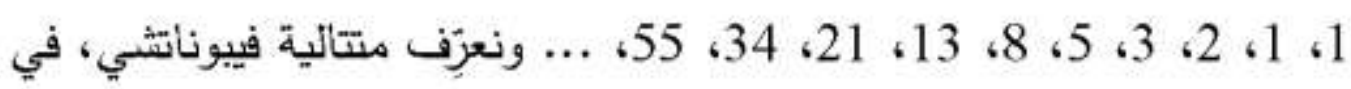

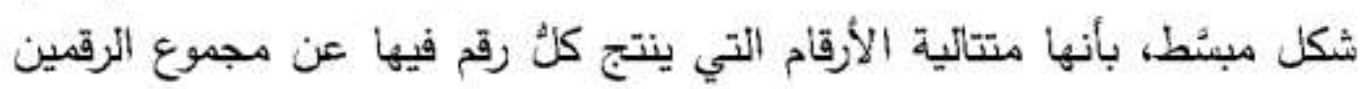

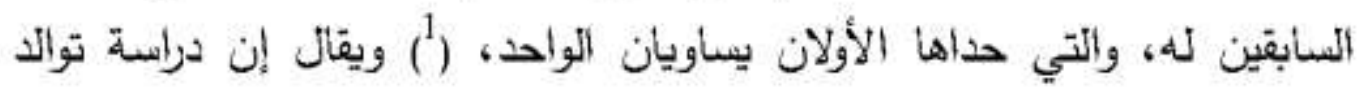

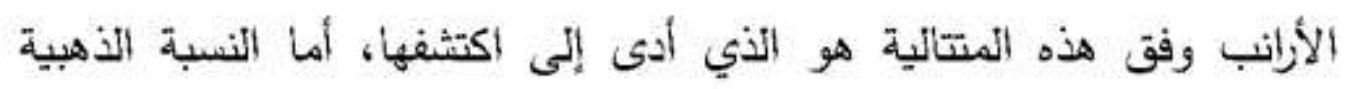

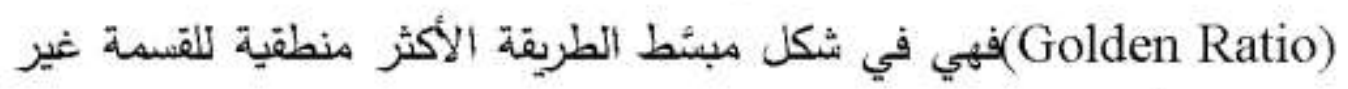
المتناظرة، أي للقسمة إلى غير النصفين، فإذا كان لدينا طول قابل للقياس

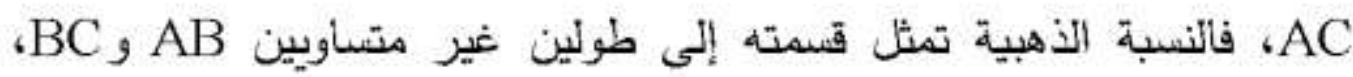
بحيث تكون نسبة الجزء الأكبر إلى الجزء الأصغر تساوي النسبة بين التطعة كلهِ AC وبين الجزء الأكبر ، أي AC A

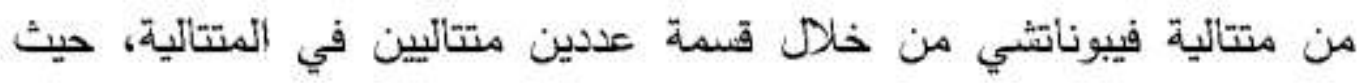
تقترب هذه النسبة من النسبة الذهبية كلما تقدمنا في المتائية (1٪1=1،

(1)- R A Dunlap :"The Golden Ratio and Fibonacci Numbers" World Scientific. publishing. 1997.p7. 
.625.1 $=8 \div 13 \quad 6 \cdot 1=5 \div 8 \quad 6660000 \cdot 1=3 \div 5 \quad 5.1=2 \div 3 \quad 2=1 \div 2$

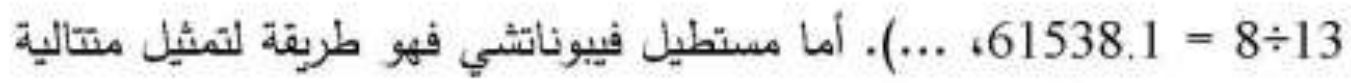

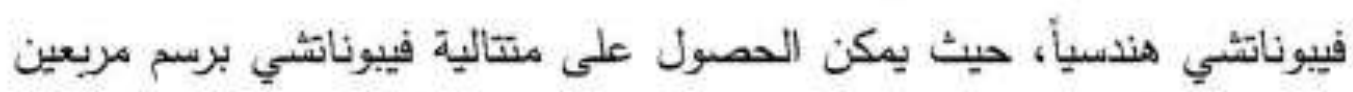

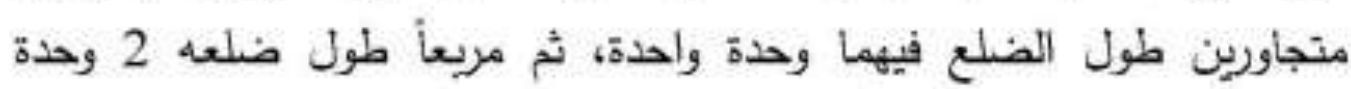
(1+1)، بحيث يكون منشأ على مربعين متجاورين، فمربعأ طول ضلعها

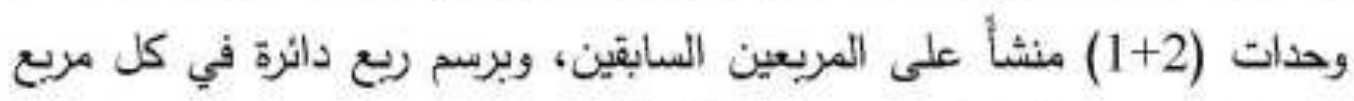
على الترتيب، ينشأ شكل حلزوني، شكل (1). ويتضح من الشكل السابق أن الخط اللولبي المصنوع في مربعات

المستطيل الذهبي تصنع خطوطاً من المركز تتزايد بمعامل النسبة الذهبية.

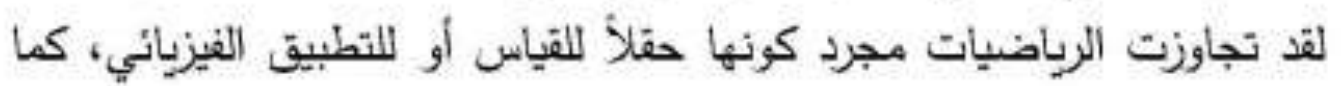

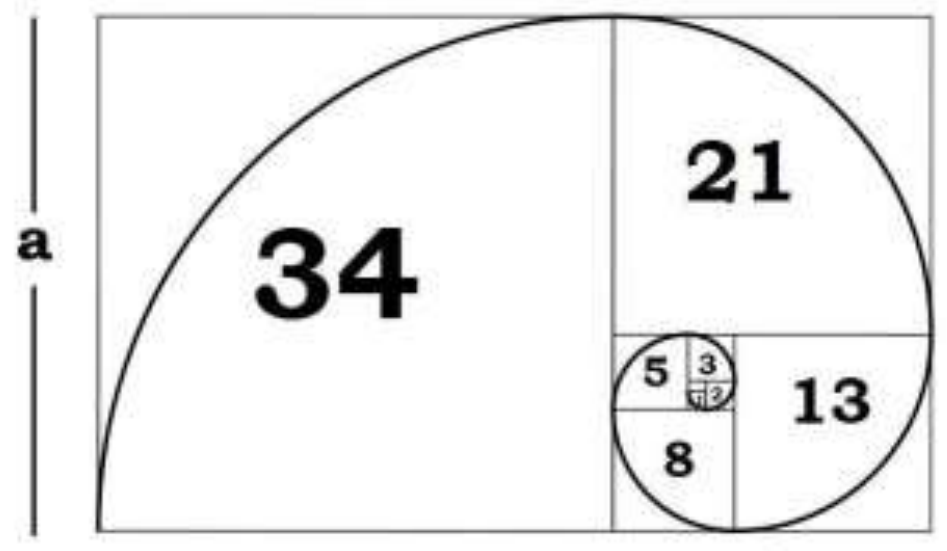

شكل (1) مستطيل فيبوناتشى الذي يمتل الروية النصرية

شكل (1) مستطيل فيبوناتشى الذي يمثل الروية النبصرية

تجاوزت المنهج الذي يقوم على النظربة والبرهان، بل تعدث نلاك لتربط تلن النظريات والمعارف الرياضية والتناسبات بقوانين الجمال وخصائصسه، لتعطي للفن ركيزة

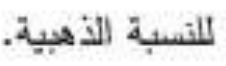
رباضضية

وسيتعرض الباحث لنموذج رباضى هندسى ذو امكانات شكلية وبنائية متميزة وغنى بالقيم والنظم والعلاقات الرقمية المقننة حسابيا كما له اصول

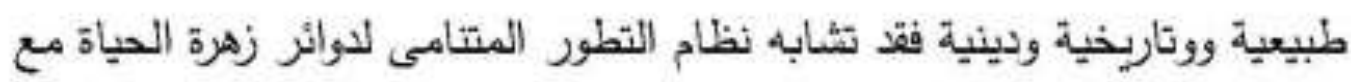

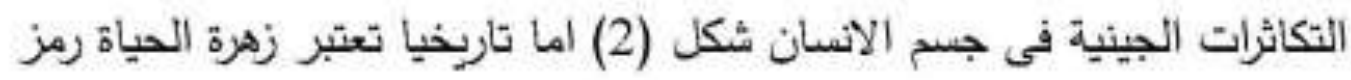




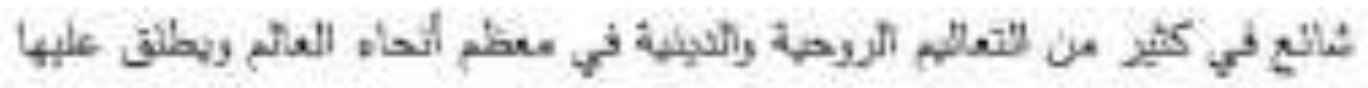

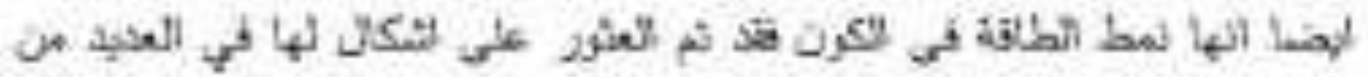

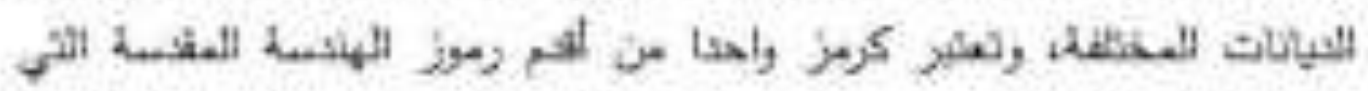

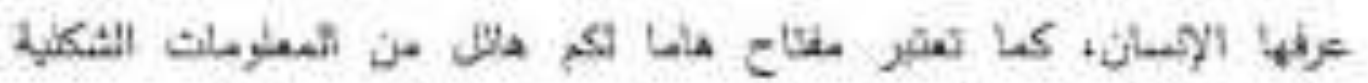

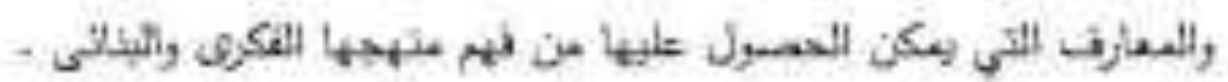

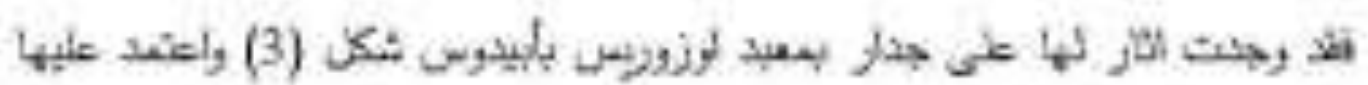

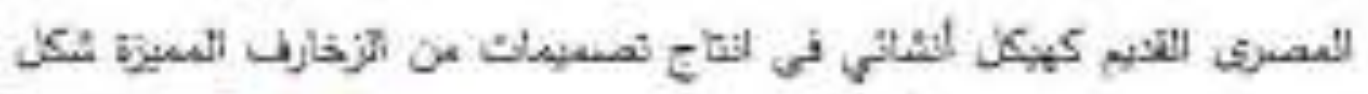

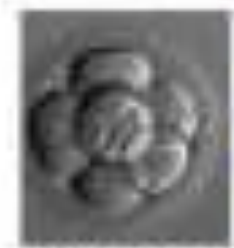

Bulangumen

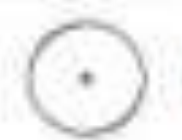

(2)
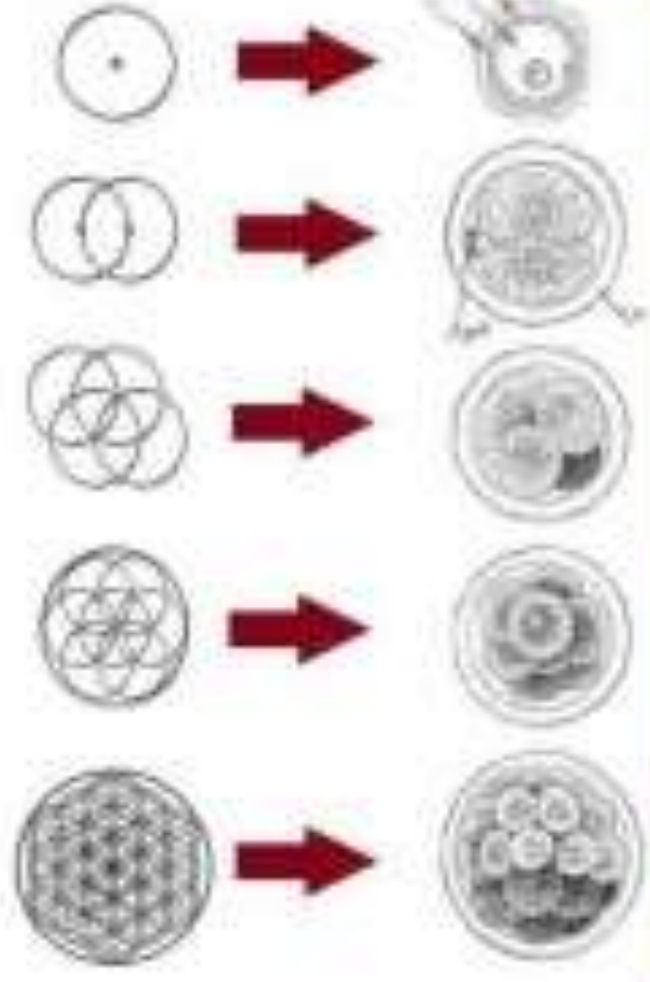

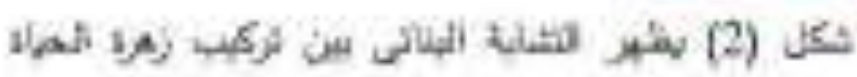

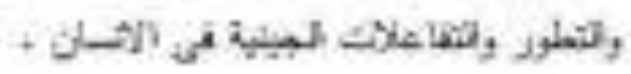

Len ets Lit (4)

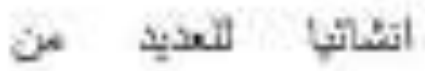

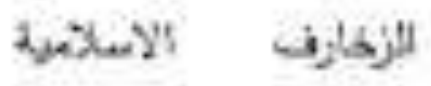
is:

the

Leonardo silis - 1452) da Vinci 1519) سفحات عنيدة

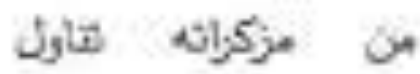

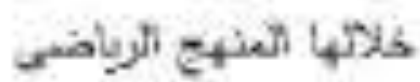

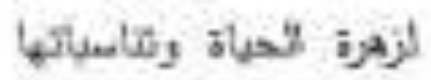

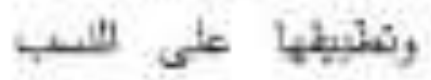
البديثية لجسبم الاتسداد - (6) (6) 

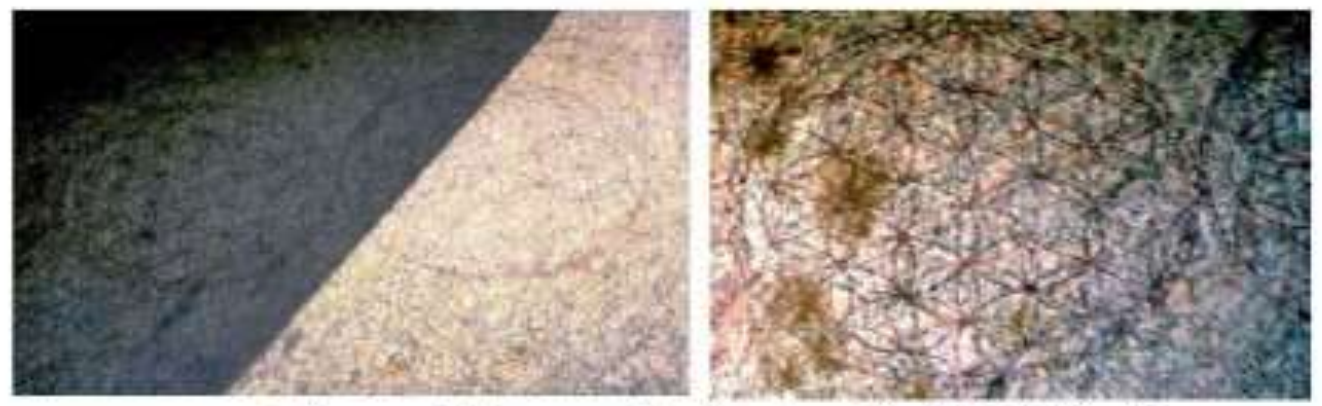

شكل (3) زهرة الحياة ، حعز على الحجر معبد أوزبربي يأبيدوس .

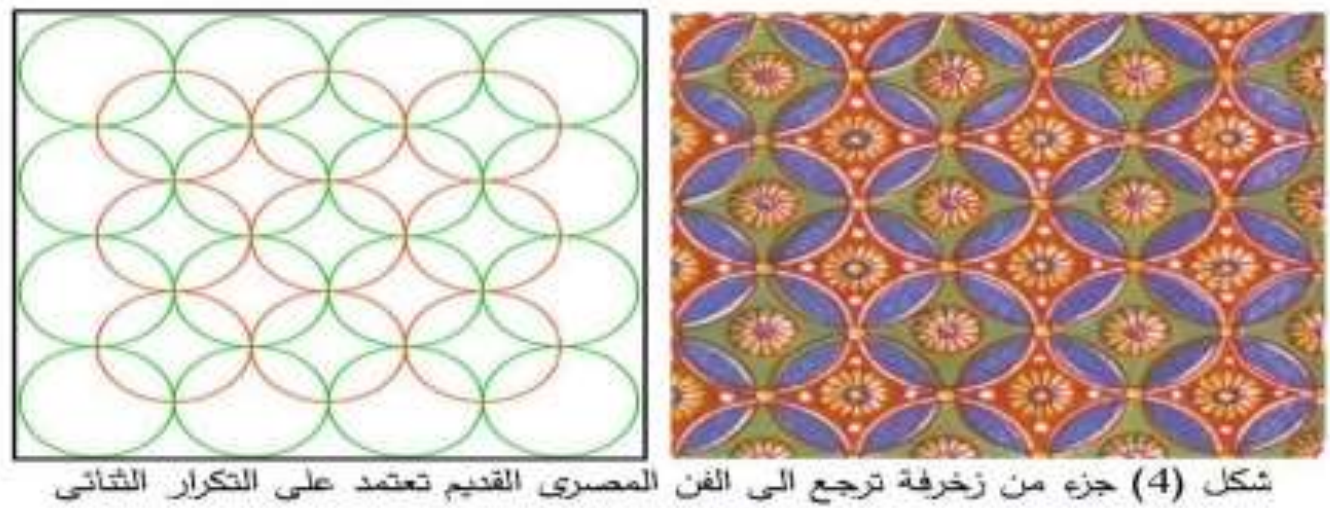
تشبكيت زهرة الحيأة.
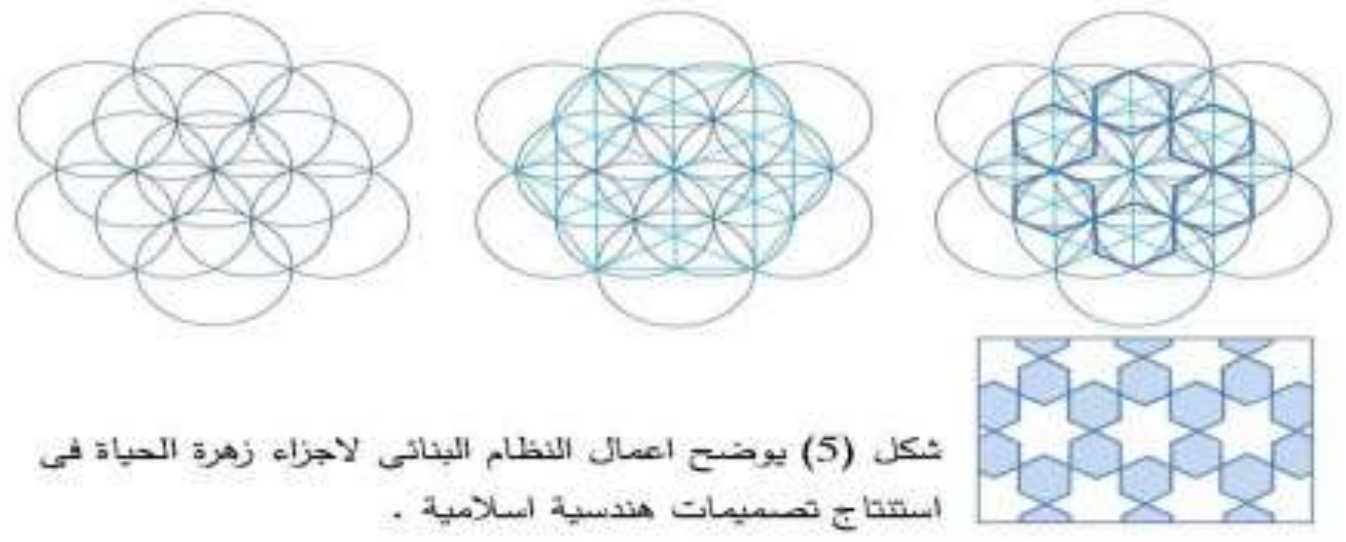

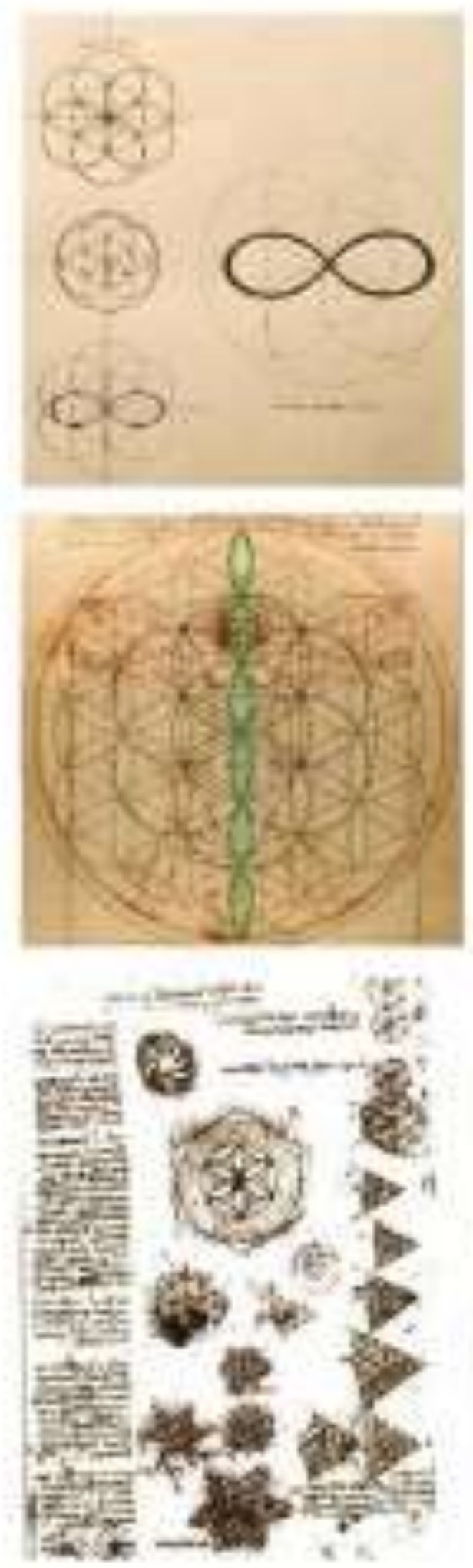

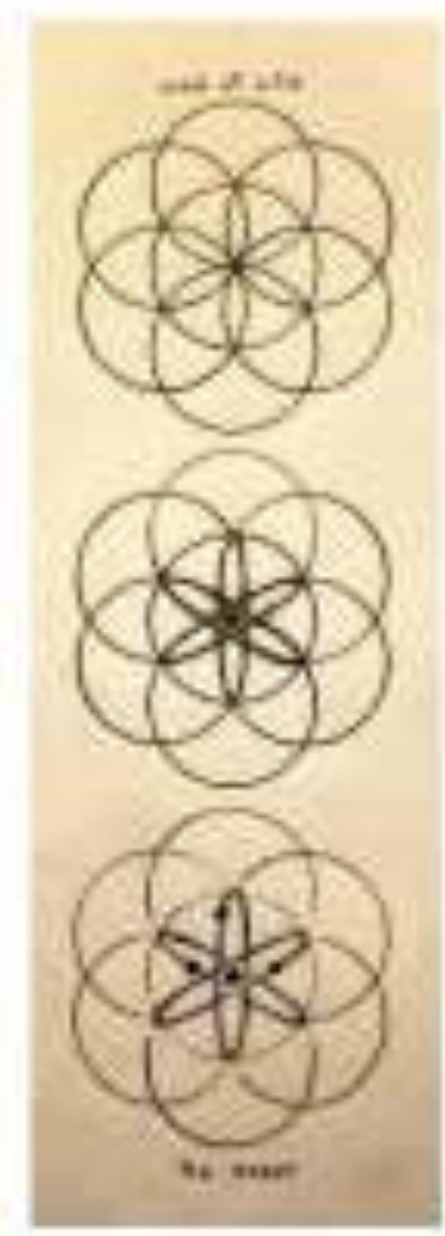

is (6) USi

(A) thes

ty whles ind

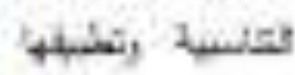
thill Leonardo Da Wind - Mower of ife'

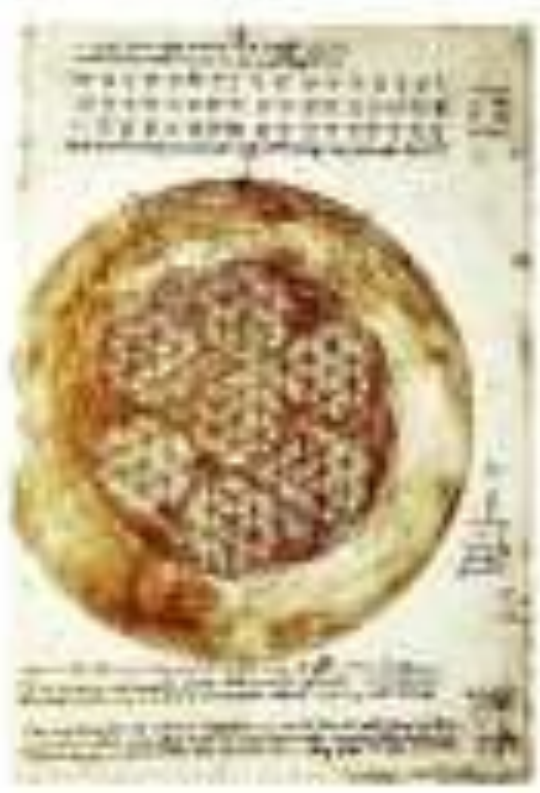


وعلى غرار الاعتماد على النظم والقوانين الرياضية فى استحاث تصميمات زخرفية ذات مرجعية منطقية يتتاول الباحث هنا نموذج يتميز The Flower of بهنسة البناء، ونظامية التكوين والانشاء, وهو زهرة الحياة life فبنائها ونموها ، ينطوي على ضبط شكلى وتقنين عقلى ، سواء فى ونى العلاقات الجزئية او هيكلية التكوين، فهى هندسيا شكل يتكون من دوائر متداخلة متعددة من نفس الحجم وتخضع وتوصف ايضا وفق منظومات عددية الرية تتحكم في نموها وتطورها الانشائى .

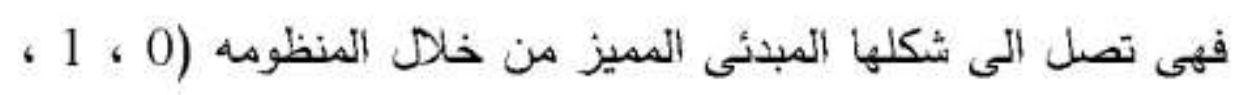

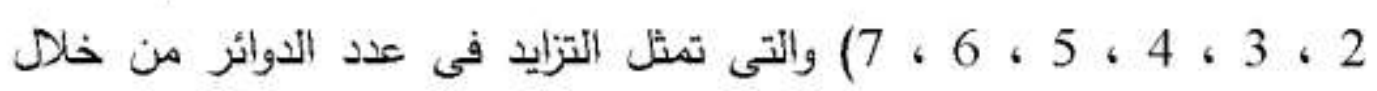
تقاطعات المحيطات مع المراكز في ترتيبات وضعية محسوبة ويبداء تكوين

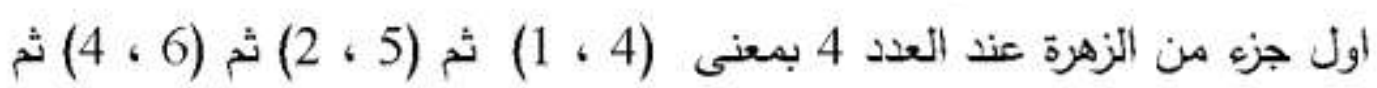

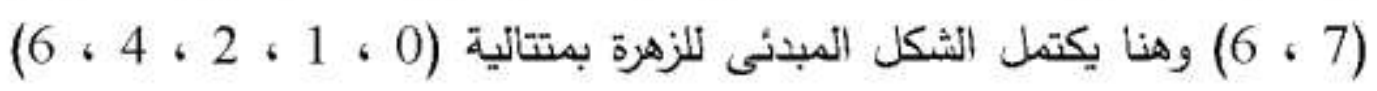

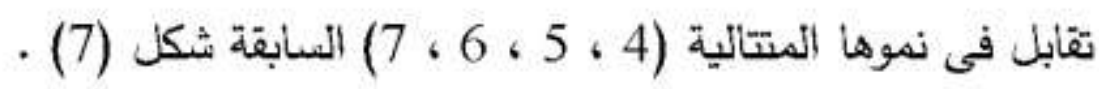

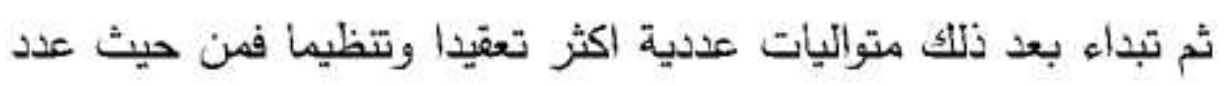

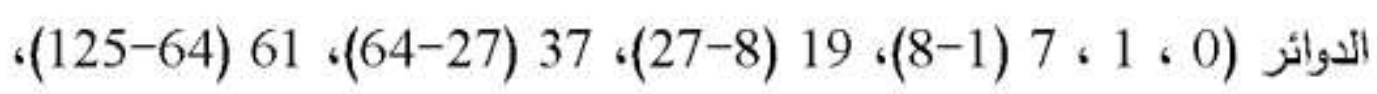

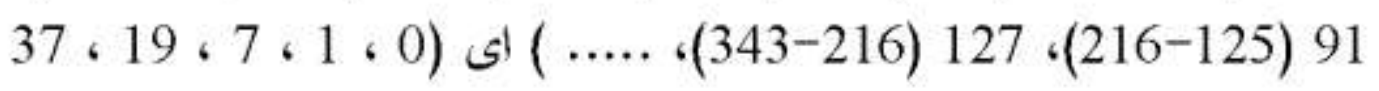

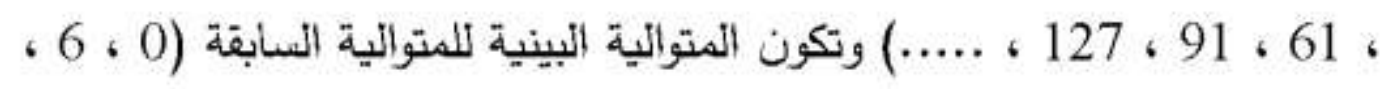

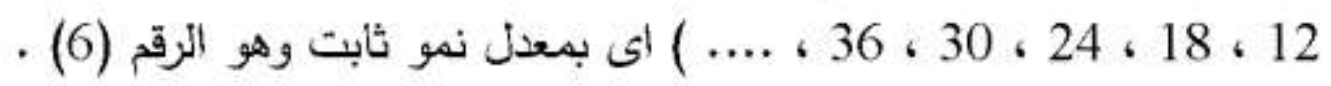

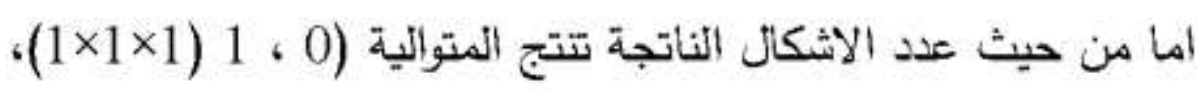
$216 ،(5 \times 5 \times 5$ (5) $125 ،(4 \times 4 \times 4) 64(3 \times 3 \times 3) \quad 27 ، 2 \times 2 \times 2) \quad 8$ ،

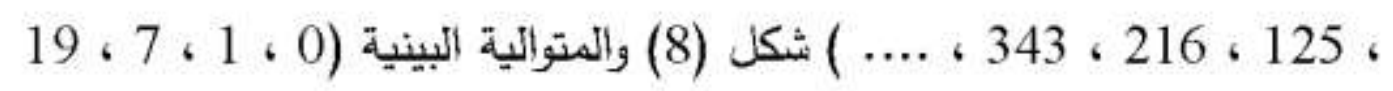

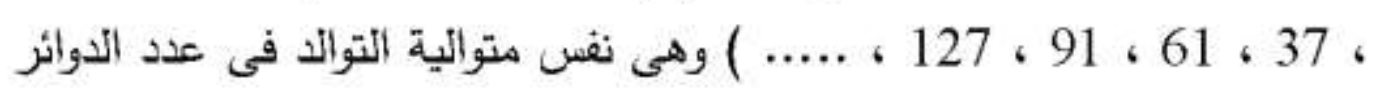


ايضا بالنسبة لعدد الخطوط المقوسة وهضاعفاتها التٓى تبداء من أكتمال شكل الزهزة تمون على النحو التالى ( 0 ، 12 ، 24 ، 36 ، 48 ، 60 ، 72

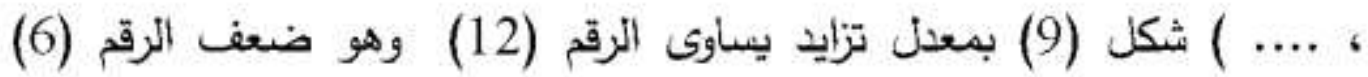
الناتج عن المتوائية البينية لعدد الدوائر . واعتمادا على ذلك الفكر المتتامى والمتوالد لتك المنظومات الرقمية المستنتجة من تكاثر زهزة الحيأة ينتج العديد من الاشكال اكثر تعقيدا وتميزا بصريا شكل (10) ب (10)

كذلك يمكن أستتاج الثكالا هنسية ثلاثية الابعاد متعددة الاوجه من خلال امتداد العلاقات الخطية بين مراكز الدوائر ومحيطاتها شكل (11) وايضا من خلال تطبيق بعض المنظومات الزقمية على اعداد من المجموعات اللونية وتوزيعها وفق منطق النمو لزهرة الحياة يمكن انتاج مجاميع لونية جذيدة متعدة

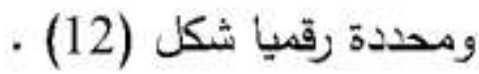




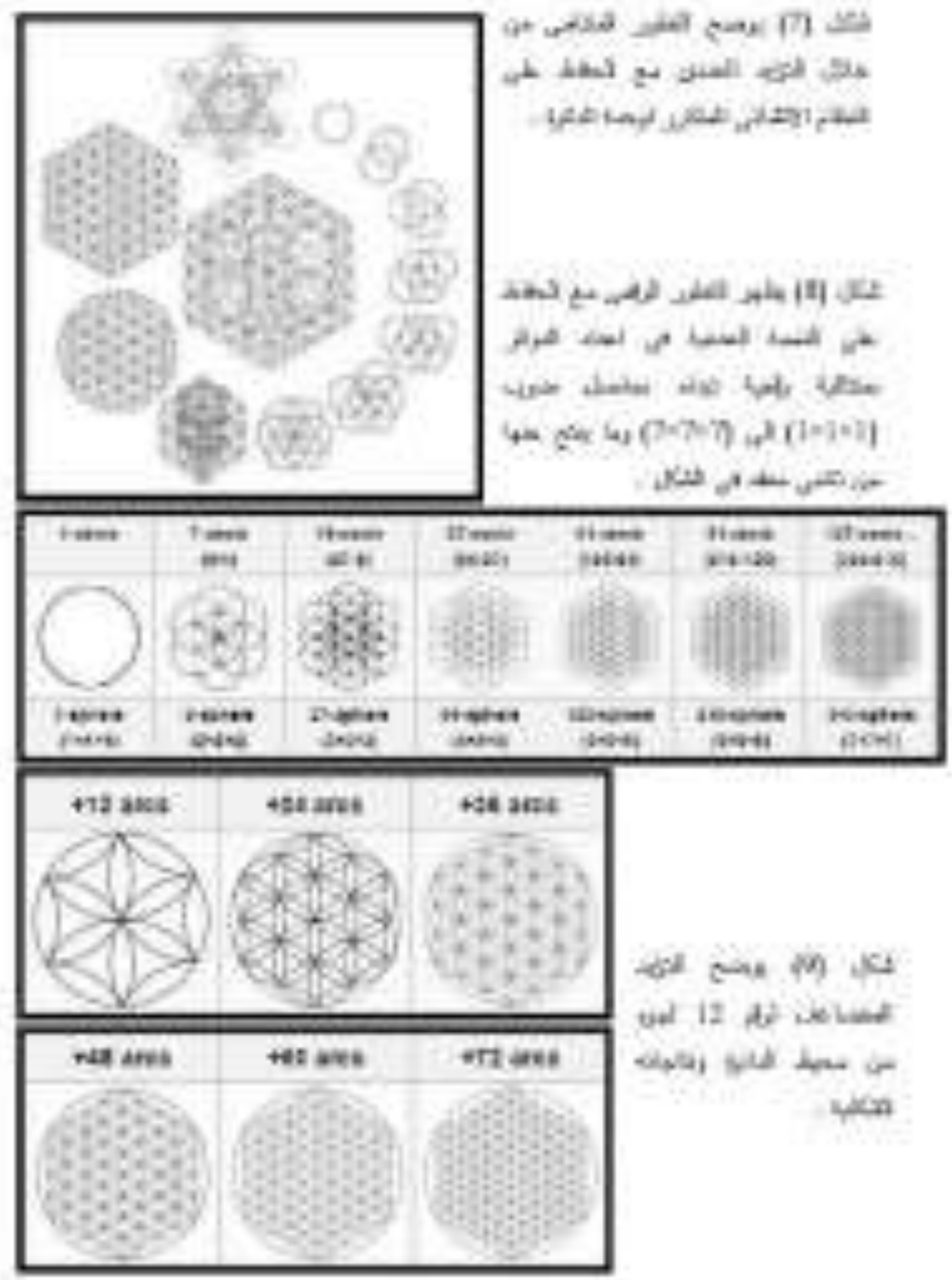


من ما سبق يؤكد الباحث على اهمية زهزة الحياة والتى يمكن الاعتماد عليها من خلال المنطلقات التالية :-

- النظام الانشائى والعلاقات الثكلية . - التطور الثكلي والبناء المتتامي - التتانبات الرياضية وهندسة التكوين - المنهج الفكري والدلالات التعبيرية . - القيم الثكلية والصياغات الخطية . - المنظومات الرقمية الناتجة عنها واعمالها فيى:• تحليل المساحات واستنتاج خلفيات شبكية . • الخطط اللونية .

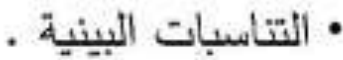
• العناصر واعدادها وعلاقاتها الشكلية.

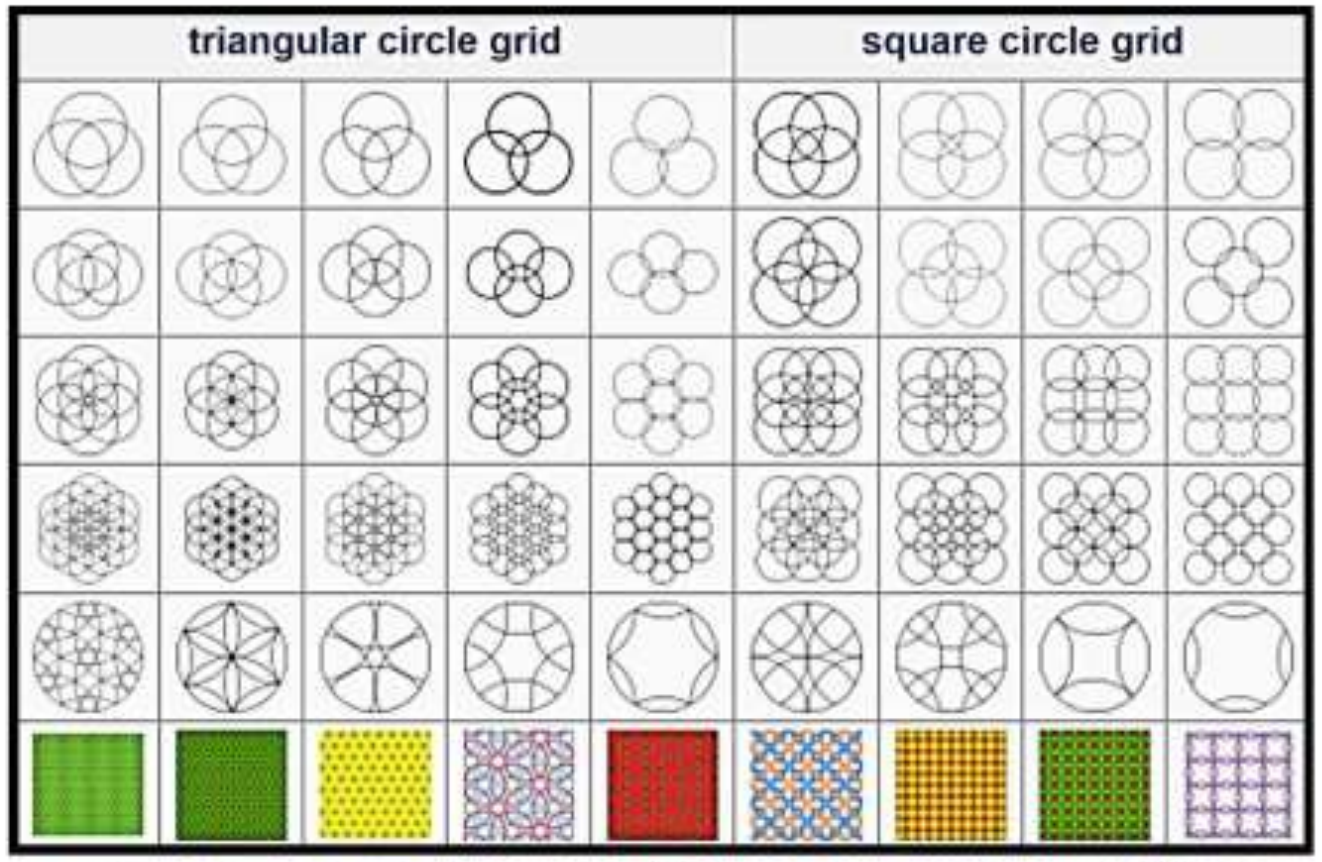

شكل (10) بعض التطبيقات والصيغ الشكلية المتنوعة للتطور العددى لوحدة الدائرة وفق منطق بئاء زهرة الحيأة . 

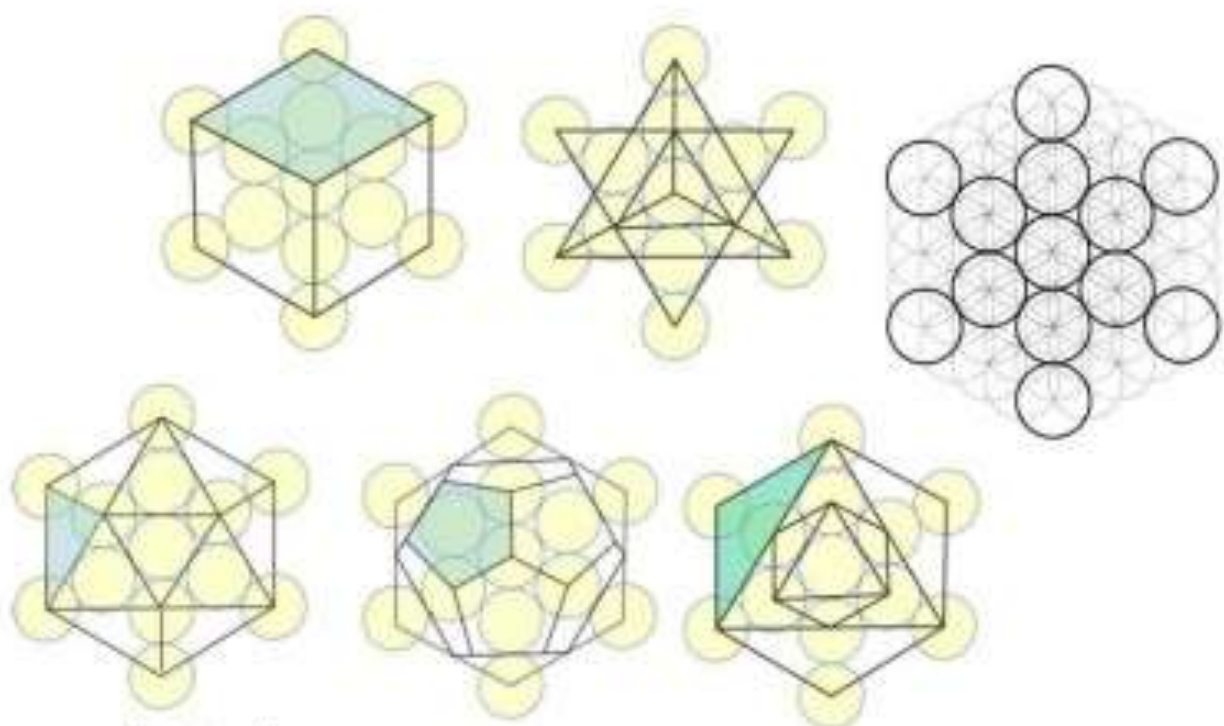

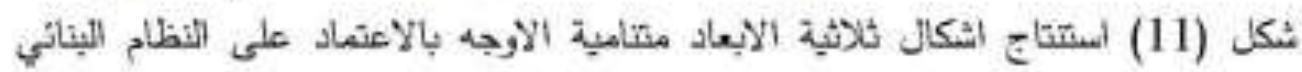

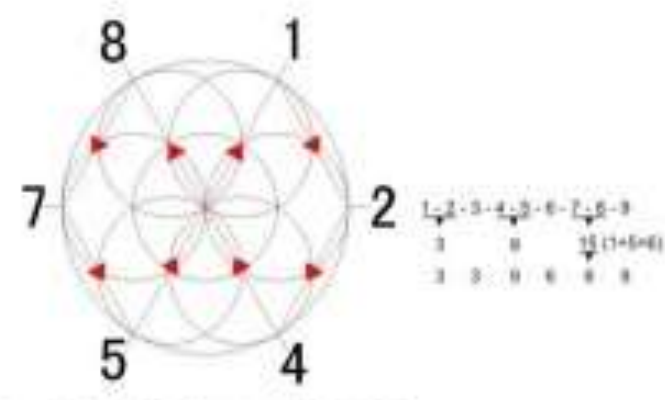

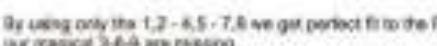
ur rapas les in mesre

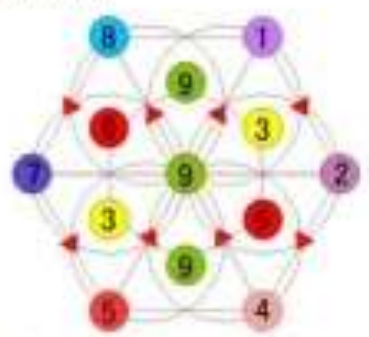

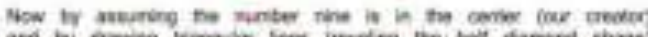

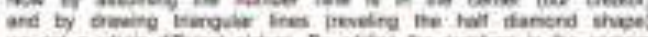

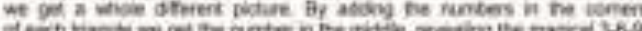

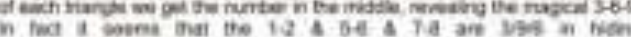

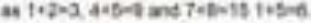

\section{(1) 3000000}

Codor porthe

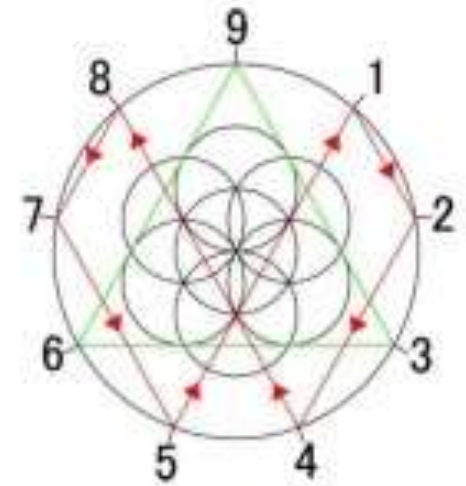

نكل (12) الاعثماد على أمثنظومة المرقمية من

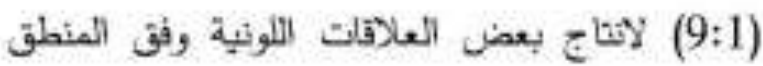

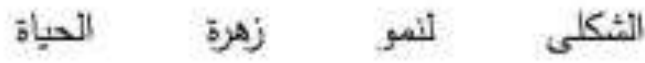

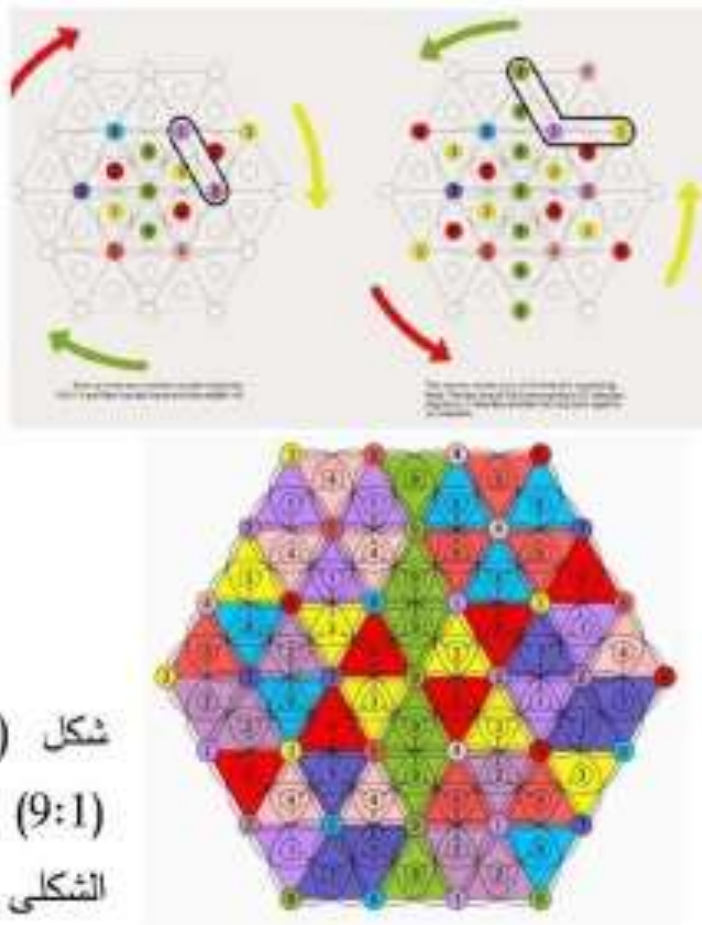


من كل ما سبق يتضح ددى الهية زهرة الحياة كنموذج رياضى له الصول

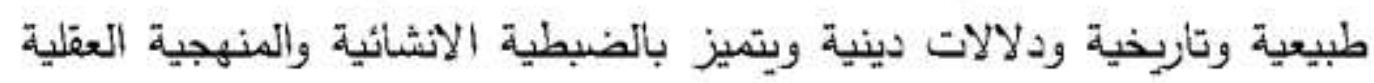
فى البناء والتكوين وما ينتج عن تحليل تطورها الثكلى من مجاميع من المنظومات العددية التتى يمكن ان تكون مرجعية فكرية رقمية وخلفية منطقية

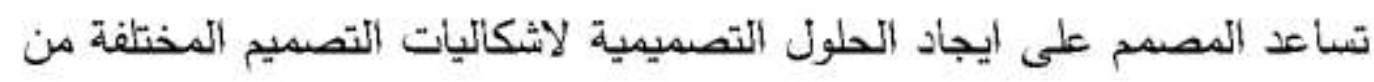

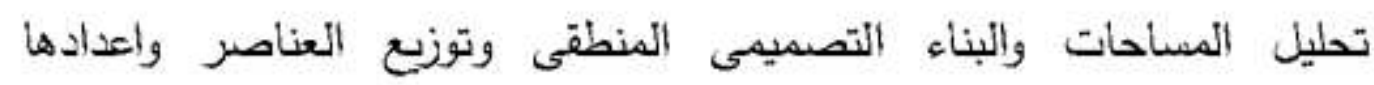

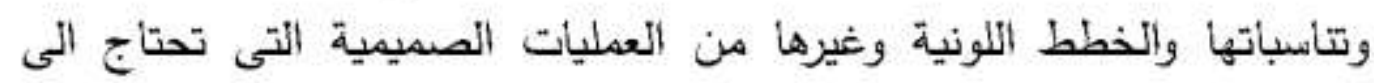

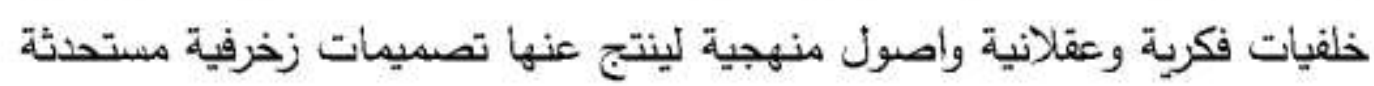
ذات مرجعية رياضية تتميز بالتقنين الثكلى والمنطق بنائى . 


\section{ثاتيا : مشكلة البحث :-}

دائما ما يحتاج المصمم إلى مصأدر فكرية ومرجعيات عقلية متجددة تمثل الخلفيات النظربة نتطبيقاته العملية وكلما كانت هذه المصادر تتبع من أصون فكرية مختلفة كلما ذاد التنوع في النتائج المرجوة لذا يحاول الباحثث في هذا البحث الكثف عن الإمكانات التشكيلية والقيم البنائية لنموذج زهرة الحياة والاعتماد عليه كمنطلق فكرى يمكن الاستفادة منه في إثراء الصياغات التصميمية المختلفة لما تتميز به من ضبطية إنشائية وتقنين شكلي وتنظيم رقمى وصولا لأفضل الحلول التصميمية التي تعتمد على التهنهج التبنائي والنظنام الانشائى لهذا التموذج، من هنا تأنى مشكلة التبحث والتي تتمثل في السؤال

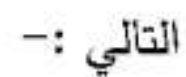

- كيف يمكن الاستفأدة من الإمكانات التشكيلية لزهرة الحياة في إثراء

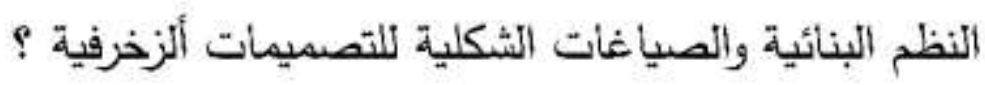

$$
\begin{aligned}
& \text { ثالثا : هاف البحث :- } \\
& \text { يهدف البحث الحالتى التى : }
\end{aligned}
$$

- استحداث تصنيمات زخرفية مبتكرة تعتمد على المنهج الفكرى والنظلام

$$
\begin{aligned}
& \text { الزياضى والانشائى لزهزة الحياة . }
\end{aligned}
$$

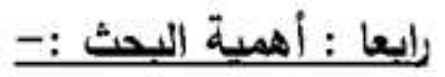

$$
\begin{aligned}
& \text { قد يسهم النبحث الحالّى فى : }
\end{aligned}
$$

- ايجأد مرجعية فكرية جديدة ذات منهجية رياضية يستطيع المصمح الاعتماد عليها في أستحداث تصميمأت زخرفية مبتكرة وتضيف مصدر جديد التى • مصنادر التصميم - إلقاء مزيدا من الضنوء على النمأذج الثكلية ذات المرجعية الرياضية لما

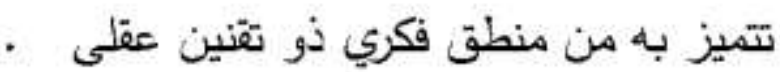




\section{- خامسا : فرض البحث -}

- يمكن أستشار التقيم البنائية والصيغ الثكلية لزهرة الحياة في أستحداث

$$
\begin{aligned}
& \text { تكوينات زخرفيه مبتكرة . }
\end{aligned}
$$

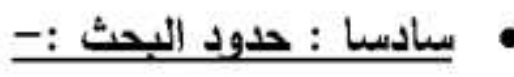

$$
\begin{aligned}
& \text { تقتصر حدود البحث على مايلى : }
\end{aligned}
$$

- الاعتماد على نموذج زهرة الحياة ونظمها الثكلية والبنائية كمصدر

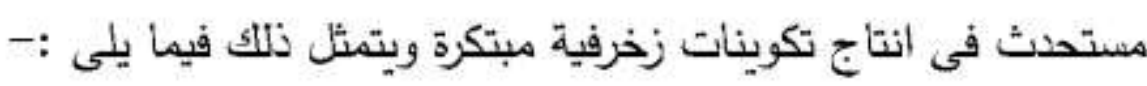

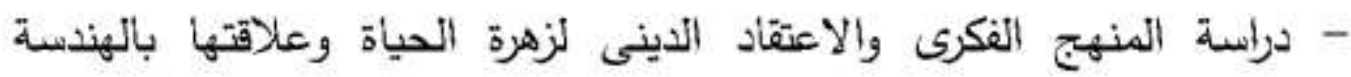
المقنسة .

- تحليل النظم النبائية والتعلاقات الانشائية والصيغ الثكلية لهذا النموذج · الزياضنى - أستخلاص الاسس وائقوانين الرياضضية الآتى تميز زهزة الحياة بصريا وعقليا

\section{-: : بابعا : منهج البحث}

- يتبع البحث المنهج الوصفي التحليلي , لتحقيق هدف التحث كمايتبع المنهج التجريبى للاجابة عن فرضه على التحو التالي :-

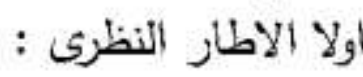

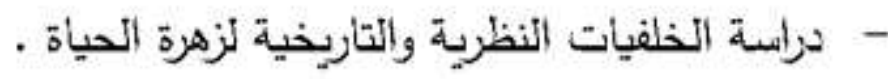
- كثف الاصول الترياضية وحصر المنظومات الرقمية التى تعتمد عليها زهرة

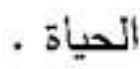

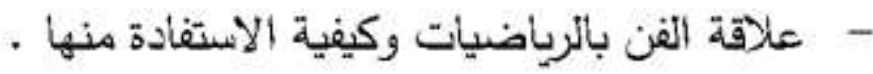

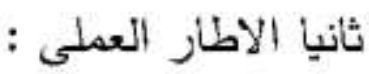
- التحليل البنائى والانثائى والثكلى لزهرة الحياة للوقوف لاستتناج قوانينها التتظيمية . - توظيف تلك النتائج فى أستحداث تكوينات زخرفية تعتمد فى مرجعيتها على الضبطية الثكلية لزهرة الحياة. 


\section{مصطات البحث:-}

\section{:The Flower of life زهرة الحياة -}

هي عبازة عن شكل هندسي يتكون من عدة دوائز متداخلة ومتماسية بثكل نظامى، تتوالد وتنمو شكليا في متوائيات عددية منظمة ومحسوبة وقد

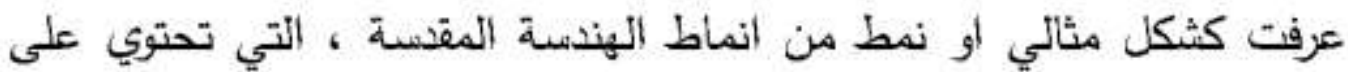
القيمة الدينية القديمة والتتي تصور الأشكال الأساسية للمكان والتزمان ولها اصول تاريخية في العديد من التفنون والحضارات المختلفة . - نظدام System -

هو الكيان المتكامل الذي يتكون هن أجزاء وعناصر متداخلة ، تقوم بينها علاقات من أجل أداء وظائف أو أنشطة تكون محصلتها النهائية بمثابة الناتج الذي يحقق النظام كله أنات.

\section{-Constructivism البنائية -}

هي مجمل العلاقات القائمة بين التفلسفة والمنطق والنظام والأسلوب في مجال ما من المجالات على أن يكون لهذه البنائية سمة خأصة ناتجة عن ارتباط كلاً

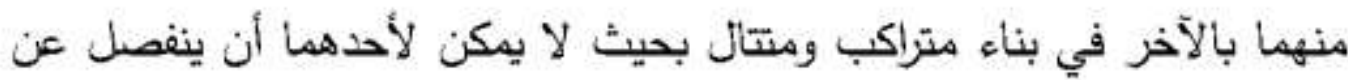
(2) الآخر (2) - (2)

\section{- Structure system النظام البنائي -}

يعد بمثابة تحليل للمحاور الرئيسية التي يبنى عليها النظام التصميمي وتلك المحأوز هي محأور رأسية وأفقية ومائلة والثمنحنيات والدوائز والنظام

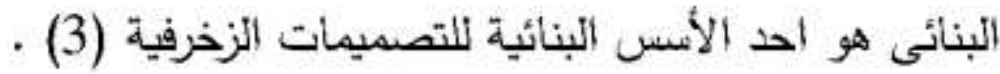

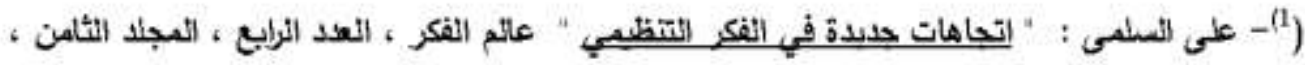

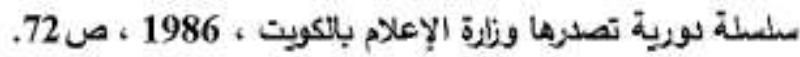

(2) - The new encyclopedia Britannica, vol 3, USA , 1985 , P , 576 .

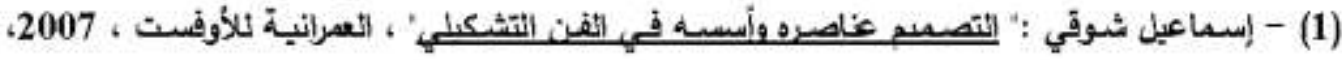




\section{- التراكيب البنائية The constructive inebriation -}

يعرف " ليف شتراوس " التزركيب البنائية أو الثركيب البنائى على أنه " الثيء

الذي يعبر عن صفات النظام فهو مكون من عدده عناصر لا يستطيع أي لئي

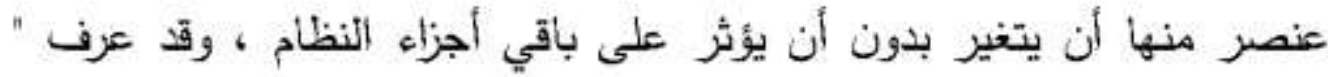

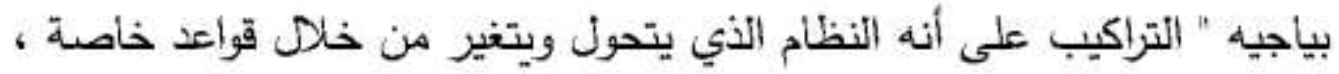

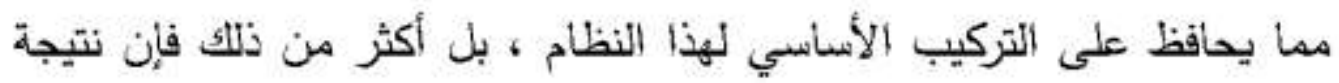
هذا التطور قد تؤدى إلى إزاء النظام الاساسسى (2) -

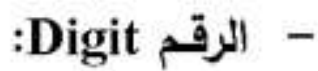

وهو الرهز الكستعل في الرياضيات للتعبير عن احد الأعداد الطبيعية البسيطة

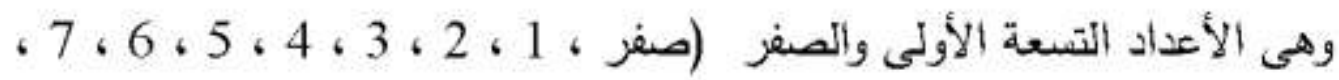
(1) $(9$ ، 8 ، 8 


\section{ه إلنتائج والتوصيات:-}

توصل الباحث بعد إنهاء هذا البحث التى مجموعة من النتائج والتوصيات

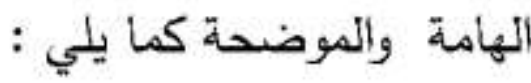

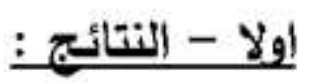

- المنهج البنائي والنتاج الثكلي لزهرة الحياة يعتبر منطلق فكرى هميز يمكن

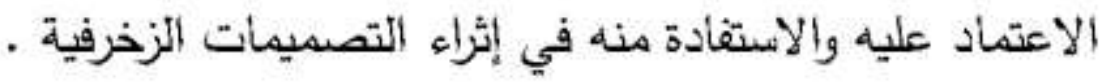

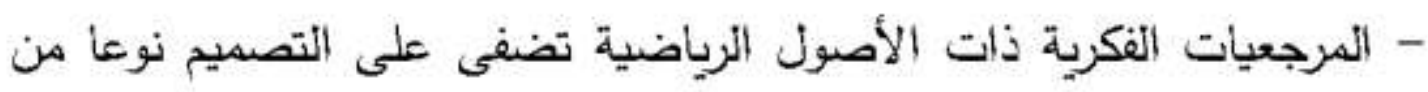
المنطقية الثكلية والضبطية الإنثائية . - المنظومات الرقمية تعد مصدر رياضيى مستحدث يمكن الاعتماد عليه فى الإنى انتاج تصميمات زخرفية منطقية البناء والتكوين .

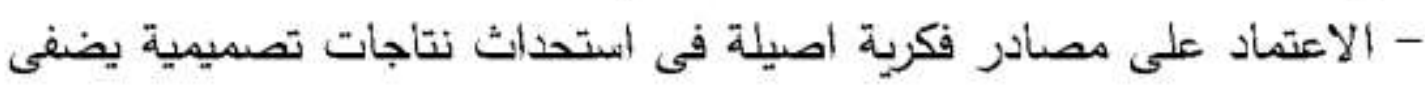

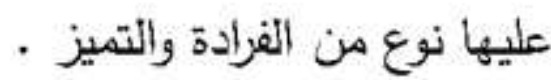

\section{ثانيا - التوصيات :}

ويوصى الباحث بما يلى :

- البحث من مرجعيات فكرية ذات منطقية رياضية يمكن الاعتماد عليها كخلفيات ومصادر معرفية ومهارية يستقى منها المصمم خبراته وأشكال مارسياته المختلفة. - تكثيف البحث العلمى حول المصادر والمنظومات الرقمية لتكوين مخزون مرجعى يستطيع الدصم الرجوع اليه والاستفادة منه . - الاهتمام بتظير المرجعيات المنطقية بتوصيفات المقررات التصميمية . 


\section{المراجي العربية:-}

1- إسماعيل شوقي :" التصميم عناصزه وأسسه في الفن التشكيلي" ، العمرانية

$$
\text { لكلوفست ، } 2007 .
$$

2- نكريا إبراهيح: " مشكلة البنية " مكتبة مصر ، القاهزة ،1975.

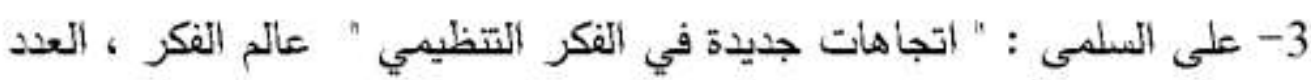

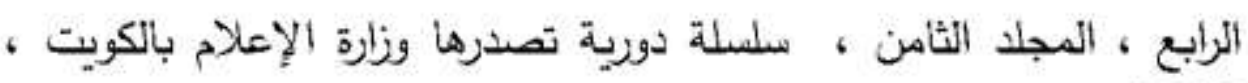

. 1986

4-شرين احسان شيرذاد :" الحركات المعمارية الحديثة الأسلوب العالمى فى

العمارة " المؤسسة العربية للدراسات والنشر ، بيروت 1999.

5- موسوعة التكنولوجيا : "الأجهزة وكيف تعل " ، 1980 .

\section{• المعلحي الأحنية:-}

1- Drunvalo Melchizedek:"The Ancient Secret of the flower of life" Light Technology Publishing, volume 2, 2000.

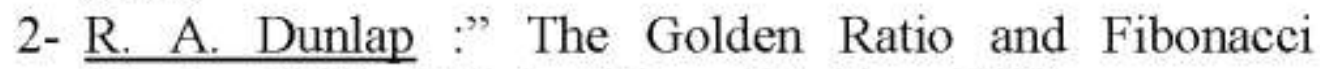
Numbers" World Scientific, publishing, 1997.

3- Drunvalo Melchizedek:" The Ancient Secret of the Flower of Life" Light Technology Publishing, Volume 1, 1998.

4- Drunvalo Melchizedek:" Serpent of Light "Accessible publishing, Canada, 2010.

5- John A. Adam :" Mathematics in Nature : Modeling Patterns in the Natural World " Published by Princeton University Press. New York, 2003.

6- Gilbert A.:" The Mathematical Nature of Living World: The Power of Integration "World Scientific Publishing Co .PTE .LTD, USA, 2004.

7- The new encyclopedia Britannica, vol 3 , USA, 1985. 


\section{المواقع الاليكتشونية :-}

1- http://www divinetemplatecreations.com/sacred geometr $\mathrm{y} / 1-9 . \mathrm{html}$.

2- https://en.wikipedia.org/wiki/Overlapping circles grid\# Metatron $27 \mathrm{~s}$ cube.

3- https://blog.etemetaphysical.com/seedoflife/.

4- http://palmicinarsson.blogspot.com/2014/06/theamazing-3-6-9-and-flower-of-life.html. 